\title{
Influence of Soft Drinks with Low pH on Different Ni-Ti Orthodontic Archwire Surface Patterns
}

\author{
C. Abalos, A. Paul, A. Mendoza, E. Solano, C. Palazon, and F.J. Gil
}

(Submitted November 5, 2011; in revised form May 16, 2012; published online July 20, 2012)

\begin{abstract}
The aim of this study was to determine the influence of soft drinks on the surface of Ni-Ti archwires and their corrosion behavior. Archwires with different patterns (smooth, scratch, dimple, and crack) were selected and characterized by scanning electron microscopy and laser confocal microscopy. Immersion tests were performed in artificial saliva (pH 6.7) with a soft drink with a $\mathrm{pH}$ of 2.5 for 28 days. The results showed an increase in the surface defects and/or roughness of the dimple, crack and scratch patterns with the immersion times, and a decrease in corrosion resistance. A relationship between the surface pattern and the extent of the corrosion in $\mathrm{Ni}$ - Ti archwires with soft drinks at low $\mathrm{pH}$ has been demonstrated. Pattern should be taken into account in future studies, and manufacturing processes that produce surface defects (especially cracks) should be avoided.
\end{abstract}

Keywords corrosion, Ni-Ti, surface

\section{Introduction}

The biocompatibility of nickel-titanium alloys (Ni-Ti) near equiatomic composition is good in artificial saliva, Ringer's solution, and physiological saline solution (Ref 1). Nevertheless, the corrosion resistance of $\mathrm{Ni}-\mathrm{Ti}$ alloys decreases in acid saliva (Ref 2-4) and chlorine (Ref 5) or fluoride-containing solutions (Ref 5-15). Corrosive agents deteriorate the passive film of the titanium oxide surface (Ref $7,12,14,15$ ), decreasing corrosion resistance of the alloy and hence its biocompatibility (Ref 1-3).

In the last decade, many studies have examined the factors that influence $\mathrm{Ni}-\mathrm{Ti}$ alloys exposed to fluoride. It is well known that the outer titanium oxide layer is degraded by hydrogen absorption (Ref 14). Also, the effects of exposure time (Ref 13, 14), fluoride concentration (Ref $6,7,12$ ) and a more acidic $\mathrm{pH}$ (Ref 12, 14), as well as their relationships, have been studied (Ref 13). A pH-dependent critical concentration has been defined (Ref 10, 11) that can degrade the passive film. Nevertheless, in relation to carbonated drinks, only studies on

C. Abalos, Department of Dental Materials, School of Dentistry, University of Seville, Seville, Spain; A. Paul, Department of Mechanical and Materials Engineering, School of Engineering, University of Seville, Seville, Spain; A. Mendoza, Department of Pediatric Dentistry, School of Dentistry, University of Seville, Seville, Spain; E. Solano and C. Palazon, Department of Orthodontics, School of Dentistry, University of Seville, Seville, Spain; and F.J. Gil, Department of Materials Science and Metallurgical Engineering, Technical University of Catalonia, Diagonal 647, 08028 Barcelona, Spain. Contact e-mail: francesc.xavier.gil@upc.edu. the enamel coating that affects adherence to brackets can be found in the literature. Such drinks are a part of the diet of young people receiving orthodontic treatment, and can also degrade the orthodontic archwire surface.

When the passive film is broken, corrosion takes place. As a consequence, the release of metallic ions into the medium (Ref 3, 6, 10, 15, 16), surface morphological changes (Ref 6, $13,14)$ including an increase in roughness (Ref 3, 6) and friction coefficient between the archwire and the bracket (Ref 17), are produced. In these effects, the wire surface plays an important role in corrosion, although the published results are controversial. Previous studies (Ref 3, 16, 18) point to surface defects produced during the wire manufacturing process as preferential corrosion areas, while other authors have reported no such evidence (Ref 7, 19). Some investigators (Ref 20) consider archwire roughness to be an indicator of the tendency toward corrosion, although other studies (Ref $3,6,7,19)$ have found no such relationship when including residual stresses and the degree of homogeneity as corrosion accelerators (Ref 7, 19). This is to say that different archwire surfaces have a better or worse response to corrosive fluoride. Thus, the archwire manufacturer is a variable in itself (Ref 6, 19). The main objective of this study was to determine whether soft drinks with a low $\mathrm{pH}$ cause corrosion of $\mathrm{Ni}-\mathrm{Ti}$ wires.

The wire surface, surface defects, and roughness are related to the manufacturing processes (Ref 6) that lead to different surface finishes (Ref 21). A second objective of the present study was to investigate the influence of the surface (surface defects and roughness), as a result of the manufacturing process, upon the corrosion of Ni-Ti archwires. Different commercial brands could present the same pattern. In this context, the influence of each pattern upon soft drink corrosion was studied by means of surface analysis (scanning electron microscopy), roughness characterization (laser scanning confocal microscopy), and corrosion tests. The main hypothesis is that different surface patterns, derived from different manufacturing processes, will respond differently to corrosion produced by soft drinks. 


\section{Materials and Methods}

\subsection{Preliminary Study}

The surfaces of $16 \mathrm{Ni}$-Ti archwires $(0.016 \times 0.022$ inches $)$ from nine commercial brands were studied in the as-received condition (Ref 22) (Table 1). The surface morphology and composition were evaluated by scanning electron microscopy (SEM) (Philips XL-30 Philips, Eindhoven, Netherlands) and energy dispersive spectrometry (EDS) (Edax International, Mahwah, USA), while roughness was measured using a laser scanning confocal microscope system (LSCM) (Leica TCSSP2, Wetzlar, Germany).

The archwires were classified according to their surface patterns using 18 variables. Five variables were found to be correlated to the pattern: dimples, scratches, cracks, pores, and smooth/no defect. As a result, the Ni-Ti archwires were classified according to these five patterns (Table 1) depending on the predominant surface defects. The different surface defects are determined in the following way: As-received material can be observed in Fig. 1a. Pore is a deep, usually rounded defect. Micropore is a pore with a diameter of less than one micrometer. Dimple is a small hole, an elliptical or rounded depression on the surface similar to the dimples in a golf ball (Fig. 1c). Crack is a long, deep fissure with irregular edges and variable width (Fig. 1e). Lastly, scratch is a long fissure with smooth edges and constant width, in which the bottom is clearly visible (Fig. 1g).

\subsection{Material and Immersion Test}

Eight Ni-Ti wires with near equiatomic compositions made by different manufacturers were used in this study. Each surface pattern (dimple, scratch, crack, pore, and smooth/no defect) corresponded to two different commercial brands (Table 1). The porous surface pattern was eliminated from this study because there was only one manufacturer. For the tests, use was made of five samples of different archwires from the same batch $(n=40)$. The samples were $20 \mathrm{~mm}$ segments extracted from the straight part of the arch. Prior to immersion testing, each specimen was cleaned and degreased for 5 min in acetone.

Samples were placed in a propylene tube $(15 \mathrm{~mL})$ with $2 \mathrm{~mL}$ of artificial saliva modified by Fusayama (saliva composition: $\mathrm{NaCl}(0.4 \mathrm{~g} / \mathrm{L}), \mathrm{KCl}(0.4 \mathrm{~g} / \mathrm{L}), \mathrm{CaCl}_{2} \cdot 2 \mathrm{H}_{2} \mathrm{O}(0.906 \mathrm{~g} / \mathrm{L})$, $\mathrm{NaH}_{2} \mathrm{PO}_{4} \cdot \mathrm{H}_{2} \mathrm{O}(0.690 \mathrm{~g} / \mathrm{L}), \mathrm{Na}_{2} \mathrm{~S} \cdot 9 \mathrm{H}_{2} \mathrm{O}(0.005 \mathrm{~g} / \mathrm{L}), \mathrm{KSCN}$ $(0.3 \mathrm{~g} / \mathrm{L})$, and urea $(1 \mathrm{~g} / \mathrm{L})(\operatorname{Ref} 2,3,7,8))$ at pH 6.7 (micropH 2001, Crison Instrument S.A., Barcelona, Spain) for 28 days at $37{ }^{\circ} \mathrm{C}$. During this time, the samples were placed in $15 \mathrm{~mL}$ propylene tubes with $2 \mathrm{~mL}$ of soft drink with a $\mathrm{pH}$ of 2.5 every 3 days (10 days in total). The immersion sequence was: 1 min in soft drink followed by rinsing of artificial saliva for $3 \mathrm{~min}$ (5 times), according to the Van Eygen protocol (Ref 23). The total immersion time was $50 \mathrm{~min}$ in soft drink corresponding to the consumption of one can of soft drink per day for 28 days (Ref 24). During this process, after each immersion in soft drink, the specimens were placed in fresh artificial saliva used in this experiment.

\subsection{Surface Characterization}

The surface topography of the Ni-Ti archwires was examined before and after the immersion tests. SEM micrographs and were taken of representative degraded areas of the surface. The images were used to measure the surface occupied by each defect (dimples, scratches, cracks, and pores) in three different areas of $10,000 \mu \mathrm{m}^{2}$. The three measurements were then averaged. Thus, five samples per brand of wire $(n=40)$ and three areas per specimen were analyzed.

The surface roughness of the Ni-Ti archwires were analyzed before and after the immersion tests by means of LSCM. The microscope was previously calibrated using a Mitutoyo precision Reference Specimen (Code no. 178-601) with Ra $=3.1 \mu \mathrm{m}$ - the error coefficient being below $0.3 \%$. The images were processed using Leica Confocal software (Leica Microsystems GMBH, Wetzlar, Germany). Micrographs corresponding to 750 linear microns were taken. Five areas of $10,000 \mu \mathrm{m}^{2}$ were randomly selected from each topographic image and the roughness was measured. Ra, Rms, Rp, and Rv values obtained

Table 1 Archwires used in the preliminary and experimental studies

\begin{tabular}{|c|c|c|c|c|c|}
\hline Code & Archwire & Company & Batch & Composition(b) & Pattern \\
\hline $\mathrm{NC}(\mathrm{a})$ & Nitinol Classic(a) & 3M-Unitek & V5304 & $53.0 / 47.0$ & Smooth \\
\hline $\mathrm{RS}(\mathrm{a})$ & Reflex Superelastic(a) & TPO & 1567027 & $52.9 / 47.1$ & Smooth \\
\hline AL(a) & Align XF(a) & Ormco & 030880842 & $53.4 / 46.6$ & Dimple \\
\hline OR(a) & Orthonol(a) & RMO & $\mathrm{A} 07005$ & $52.9 / 47.1$ & Dimple \\
\hline $\mathrm{NCu}$ & NitiCu 35 & Ormco & 07E278E & 47.2/46.5/6.3(c) & Dimple \\
\hline $\mathrm{TS}(\mathrm{a})$ & Titanol Superelastic(a) & Forestadent & 28636946 & $53.9 / 46.1$ & Crack \\
\hline $\mathrm{M}(\mathrm{a})$ & Memoria(a) & Leone & 07132601 & $54.0 / 46.0$ & Crack \\
\hline $\mathrm{TM}(\mathrm{a})$ & Thermomemoria(a) & Leone & 08022001 & $53.9 / 46.1$ & Scratch \\
\hline G4(a) & G4(a) & $\mathrm{G} \& \mathrm{H}$ & 142669 & $53.3 / 46.7$ & Scratch \\
\hline $\mathrm{T}$ & Tensic & Dentaurum & 54301 & $56.5 / 43.4$ & Scratch \\
\hline $\mathrm{NH}$ & Nitinol HA & 3 M-Unitek & AP1FY & $53.0 / 47.0$ & Scratch \\
\hline RL & Ramatitan Lite & Dentaurum & 60648 & $54.5 / 45.5$ & Scratch \\
\hline M5 & M5 & $\mathrm{G} \& \mathrm{H}$ & 146755 & $53.3 / 46.6$ & Scratch \\
\hline TA & Thermaloy & RMO & A07304 & $53.4 / 46.6$ & Scratch \\
\hline $\mathrm{RH}$ & Reflex Heat-Activated & TPO & 1297060 & $53.2 / 46.7$ & Scratch \\
\hline NS & Neo Sentalloy & GAC & H326 & $53.1 / 46.8$ & Porous \\
\hline
\end{tabular}

(a)Archwires used in the experimental study. (b) $\% \mathrm{Ni} / \% \mathrm{Ti}$ (wt.\%). (c) $\% \mathrm{Ni} / \% \mathrm{Ti} / \% \mathrm{Cu}$ (wt.\%) 

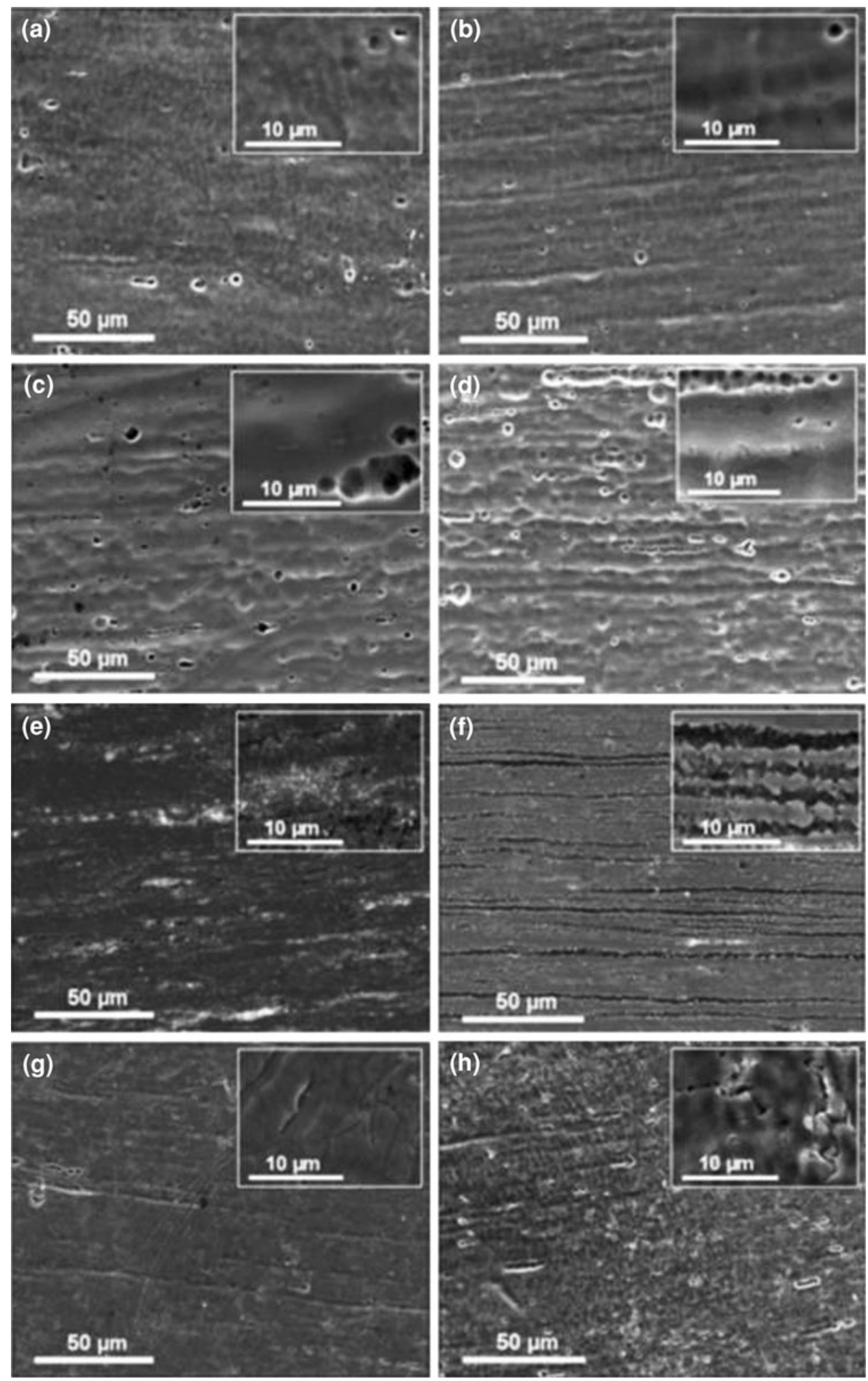

Fig. 1 Representative SEM images of Ni-Ti wires. As-received: (a) smooth pattern, (c) dimple pattern, (e) crack pattern, and (g) scratch pattern. Soft drink-treated: (b) smooth pattern, (d) dimple pattern, (f) crack pattern, and (h) scratch pattern

in each area were averaged. $\mathrm{Ra}$ and $\mathrm{Rms}$ represent the arithmetical mean of the absolute values and the root-meansquare value of the scanned surface profile, respectively. Rp and $\mathrm{Rv}$ in turn represent the highest and lowest values of the scanned profile. Thus, for roughness studies, five areas from five samples of each archwire were analyzed $(n=40)$.

\subsection{Corrosion Tests}

Archwires were sectioned to produce corrosion test samples. A 25-mm length of each archwire was cut with sterile orthodontic pliers and was isolated with wax at the point of interphase between the testing solution and the air. The corrosion tests were 


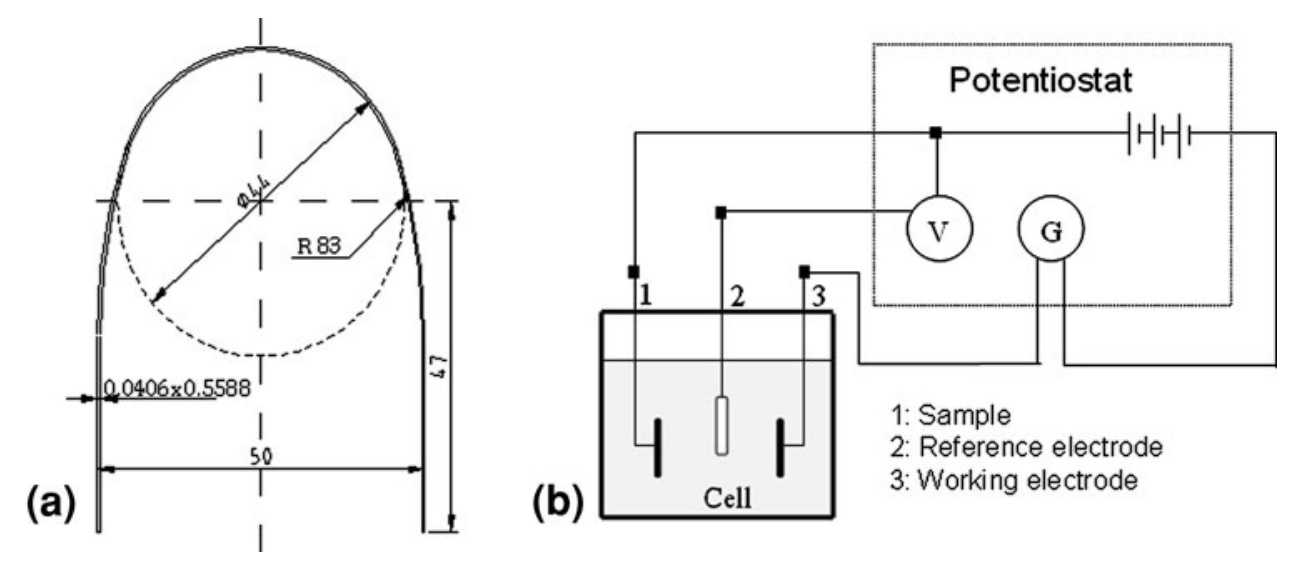

Fig. 2 Schematic representation of orthodontic archwires (a) and the electrical set-up used for measuring the electrochemical parameters (b)

performed in accordance with the ISO-standard (Ref 25) for corrosion testing.

The tests were carried out with a Voltalab PGZ 301 potentiostat (Radiometer, Copenhagen, Denmark) controlled by Voltamaster 4 software (Radiometer Analytical, Villeurbanne Cedex, France). The testing solution was artificial saliva and artificial saliva with soft drink kept at a controlled constant temperature of $37^{\circ} \mathrm{C}$. The electrical set-up used to measure the electrochemical parameters and sample geometry is represented in Fig. 2. The reference electrode was an $\mathrm{Ag} / \mathrm{AgCl} / \mathrm{KCl}$ electrode $\left(E^{\circ}=0.222 \mathrm{~V}\right)$. The auxiliary electrode used was a platinum electrode with a surface of $240 \mathrm{~mm}^{2}$ (Radiometer Analytical, Villeurbanne, France).

The open circuit potential was monitored for $3 \mathrm{~h}$ in order to allow leveling off of the value before the polarization resistance test. The Cyclic Voltammetry assay was performed by scanning the potential of the alloy of the sample at $0.25 \mathrm{mV} / \mathrm{s}$ with the minimum current set at $-1 \mathrm{~A}$ and the maximum at $+1 \mathrm{~A}$, with a minimum range set at $100 \mu \mathrm{A}$ between -300 and $+2000 \mathrm{mV}$ around the OCP value. Recordings of the variation in galvanic current density, potential, etc., were obtained, and the Tafel slopes were determined from the Evans diagrams. In order to determine these diagrams, it is very important to record the polarization curves in a pseudo-stationary manner. In this case, the $250 \mathrm{~min}$ of immersion of the specimens sufficed.

Open circuit potential $\left(E_{\text {ocp }}\right)$, corrosion potentials $\left(E_{\text {corr }}\right)$, and corrosion currents $\left(i_{\text {corr }}\right)$ were recorded for the different samples tested. These parameters are defined as:

- Open circuit potential $\left(E_{\text {ocp }}\right)$ : Potential of an electrode measured with respect to a reference electrode or another electrode when no current flows to or from the material.

- Corrosion potential $\left(E_{\text {corr }}\right)$ : Potential calculated at the intersection where the total oxidation rate is equal to the total reduction rate.

- Corrosion current density $\left(i_{\text {corr }}\right)$ : Current divided by the surface of the electrode. This is the size of the anodic component of the current which flows at the corrosion potential $E_{\text {corr }}$ Since by definition the resulting current is equal to zero at that potential, the cathodic component is of equal size, but of opposite sign. The measured resulting current being zero at the corrosion potential, the corrosion current density $i_{\text {corr }}$ can only be obtained by indirect methods, e.g., from the Tafel equation. Tafel constants $a$ and $b$ are the Tafel proportionality constants for anodic (oxidation) and cathodic (reduction) reactions of a metal.

\subsection{Statistical Analysis}

Mean values and standard deviations of each of the eight brands and the four surface patterns were computed from the data obtained during surface characterization, for the as-received archwires as well as after immersion testing. Since the archwires used had different initial values, in order to ensure valid comparison of the statistical results it was deemed appropriate to use the difference between the as-received and post-immersion test values recorded for each wire tested. Thus, the final data refer to the increases or decreases in the area occupied by the surface defects or surface roughness. Positive values imply surface degradation, while zero or negative values indicate the absence of corrosion. Statistical analysis was carried out using analysis of variance (ANOVA) and the post hoc Bonferroni test, for the comparison of mean values. Statistical significance was accepted for $\alpha \leq 0.05$. The data were analyzed using the SPSS version 14.0 statistical package (SPSS Inc., Chicago, IL, USA).

\section{Results}

Table 2 shows the results of the surface defects in the as-received archwires. Quantification was done with the surface values of each defect and the total surface defects for each archwire. The incremental value also referred to each surface pattern included for the archwires after the immersion tests in saliva with soft drink. There were significant differences in the dimple, crack, and scratch patterns. Figure 1 shows representative SEM images of the changes in the surface patterns after the corrosion tests. In the scratch pattern, pitting corrosion similar to corrosion caused by fluoride was observed (Fig. 1h). In the dimple and crack patterns there was no pitting, but an increase in the surface occupied by defects was seen. The number of dimples (Fig. 1d) and cracks (Fig. 1f) increased, respectively.

The surface roughness data (LSCM) of the archwires in the as-received and post-immersion conditions are expressed in Table 3. There was a significant difference for the cracked pattern, where there was a $34 \%$ increase in surface roughness. 
Table 2 Surface area of defects and variation ( $\Delta$ Def, obtained by subtracting average total defects) before and after immersion testing

\begin{tabular}{|c|c|c|c|c|c|c|c|c|c|}
\hline \multirow[b]{2}{*}{ Ni-Ti archwires } & \multicolumn{6}{|c|}{ Manufacturing defects (in $10,000 \mu^{2}$ ) } & \multirow[b]{2}{*}{ Pattern } & \multicolumn{2}{|c|}{$\begin{array}{c}\Delta \text { Def-saliva }+ \\
\text { soft drink }\end{array}$} \\
\hline & Cracks & Pores & $\mu$ Pores & Scratches(a) & Dimples & Total & & Mean & SD \\
\hline Reflex SE & 0 & 0 & 0.8 & 2.9 & 0 & 3.7 & Smooth & 6.7 & 16.9 \\
\hline Nitinol Classic & 0 & 174 & 1.9 & 0 & 25 & 200.1 & & & \\
\hline Orthonol & 0 & 228 & 1.5 & 0 & 6215 & 6444.5 & Dimple & $252(b)$ & 68.2 \\
\hline Align XF & 73.7 & 258 & 3,3 & 0 & 1302 & 1637 & & & \\
\hline Memoria & 577.5 & 5.1 & 1.7 & 12.8 & 176 & 773.1 & Crack & $768(b)$ & 72.7 \\
\hline Titanol SE & 264.5 & 35.6 & 1.3 & 0 & 0 & 301.4 & & & \\
\hline G4 & 37.5 & 94.95 & 5.7 & 11.2 & 0 & 149.3 & Scratch & $1306(b)$ & 46.7 \\
\hline Thermomemoria & 7.5 & 22.8 & 0.66 & 7.5 & 84.78 & 123.2 & & & \\
\hline
\end{tabular}

Dimple, crack, and scratch patterns show statistically significant variations

(a) $\mu \mathrm{m}$ per $100 \mu \mathrm{m}$ in linear scratches. (b)Mean significant difference $(p<0.05)$ by ANOVA post hoc Bonferroni test

Table 3 Surface roughness data and variation before and after immersion testing

\begin{tabular}{|c|c|c|c|c|c|c|c|c|c|}
\hline \multirow[b]{2}{*}{ Ni-Ti archwires } & \multicolumn{7}{|c|}{ Surface roughness as-received $\left(10,000 \mu \mathrm{m}^{2}\right)$} & \multicolumn{2}{|c|}{ Saliva + soft drink } \\
\hline & $\mathbf{R a}$ & Rms & $\mathbf{R v}$ & $\mathbf{R p}$ & Pattern & $\mathbf{R a}$ & Rms & $\Delta \mathbf{R a}$ & $\Delta \mathrm{Rms}$ \\
\hline Reflex SE & 0.22 & 0.31 & 2.31 & 1.20 & Smooth & $0.32(0.13)(a)$ & $0.45(0.18)$ & $-0.03(0.01)$ & $-0.04(0.01)$ \\
\hline Nitinol Classic & 0.46 & 0.61 & 3.46 & 2.76 & & & & & \\
\hline Orthonol & 1.32 & 1.71 & 8.45 & 4.53 & Dimple & $1.01(0.35)$ & $1.35(0.47)$ & $0.01(0.01)$ & $0.01(0.01)$ \\
\hline Align XF & 0.70 & 0.95 & 7.60 & 4.09 & & & & & \\
\hline Memoria & 0.44 & 0.60 & 4.30 & 2.23 & Crack & $0.35(0.13)$ & $0.48(0.17)$ & 0.12 (b) (0.04) & $0.14(b)(0.04))$ \\
\hline Titanol SE & 0.25 & 0.37 & 3.33 & 1.18 & & & & & \\
\hline G4 & 0.41 & 0.53 & 3.75 & 2.9 & Scratch & $0.42(0.11)$ & $0.54(0.14)$ & $0.01(0.01)$ & $0.03(0.01)$ \\
\hline Thermomemoria & 0.43 & 0.57 & 3.93 & 2.74 & & & & & \\
\hline
\end{tabular}

Crack pattern shows statistically significant variations

(a)Standard deviations are given in parentheses. (b)Mean significant difference $(p<0.05)$ by ANOVA post hoc Bonferroni test

In the crack pattern, Ra changed from $0.35 \mu \mathrm{m}$ in the as-received archwires to $0.47 \mu \mathrm{m}$ in the post-immersion samples. Figure 3 provides representative LSCM images of the four patterns studied.

The results obtained for $E_{\text {corr }}, i_{\text {corr }}$, and $E_{\text {ocp }}$ during corrosion testing are presented in Table 4.

The archwires tested in artificial saliva clearly showed greater resistance to corrosion than those tested in artificial saliva with soft drink. For the smooth archwires the difference in $E_{\text {corr }}$ due to immersion in soft drink was about $100 \mathrm{mV}$. However, for the surface with dimples the value was about $150 \mathrm{mV}$, and for the crack and scratch surfaces it was around $200 \mathrm{mV}$. The defects with more internal energy (cracks and scratches) are more sensitive to corrosion.

The archwires with scratches and cracks showed the greatest tendency towards corrosion, with average values of $-650 \mathrm{mV}$ in artificial saliva and $-850 \mathrm{mV}$ with soft drink. The archwires with a smooth surface were found to be less resistant to corrosion, with an $E_{\text {corr }}$ of -515 and $-600 \mathrm{mV}$, in artificial saliva and with soft drink, respectively.

The minimum current density corresponded to the smooth pattern $\left(-3.85\right.$ to $\left.-3.0 \mu \mathrm{A} / \mathrm{cm}^{2}\right)$, while the maximum values were observed in the scratch patterns $\left(-0.59\right.$ to $\left.-0.22 \mu \mathrm{A} / \mathrm{cm}^{2}\right)$ in artificial saliva. The presence of soft drink produced a decrease in both type of patterns (between 0.3 and $1 \mu \mathrm{A} / \mathrm{cm}^{2}$ ). The open current potential values showed great variability between the measurements obtained. However, the values of the smooth and dimple patterns were higher than those of the crack and scratch patterns.

\section{Discussion}

In relation to the methodological design, the equivalent of one soft drink was used as average daily consumption. Nevertheless, consumption has been estimated to be 12 cans per week per person (565 mL/day) (Ref 26). In American teenagers between the ages of 12 and 19 years, consumption can be as high as $600-800 \mathrm{~mL} /$ day (Ref 27). Thus, the average consumption used in this study can be regarded as regular.

In relation to the immersion test, no previous studies involving the exposure of orthodontic wires to carbonated drinks have been found. Due to the lack of data, in vitro enamel exposure protocols were used (Ref 23,24$)$. Accordingly, the corrosion results obtained are not due to excessive exposure to the media. Furthermore, it is suspected that during orthodontic treatment, the contact time could be even higher than for 


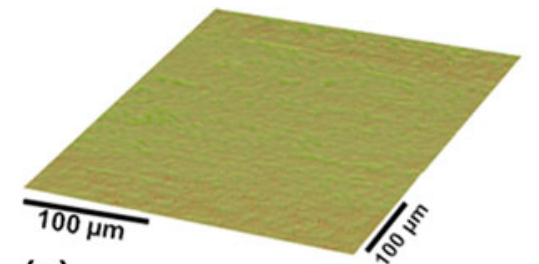

(a)

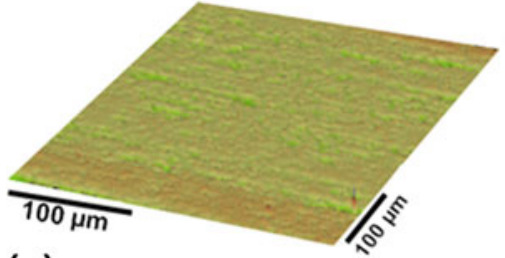

(c)

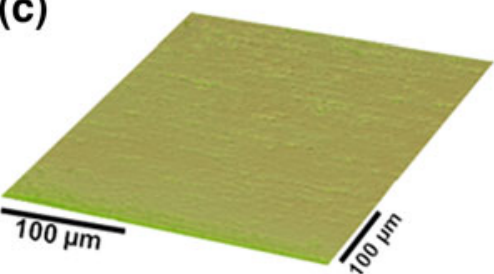

(e)

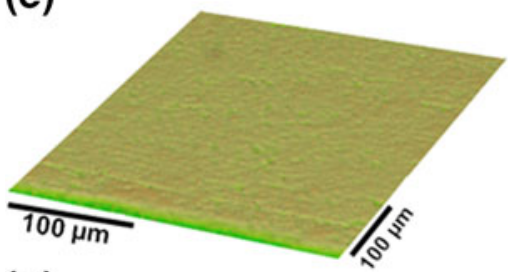

(g)

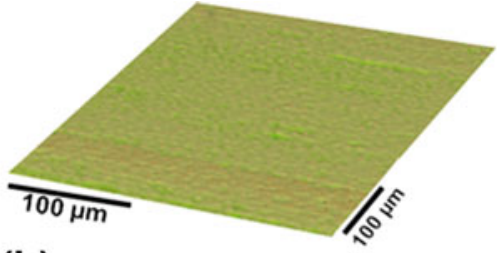

(b)

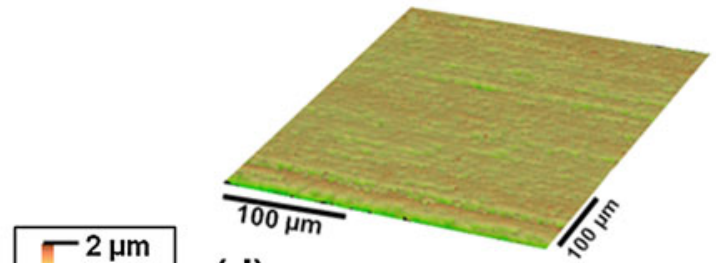

(d)

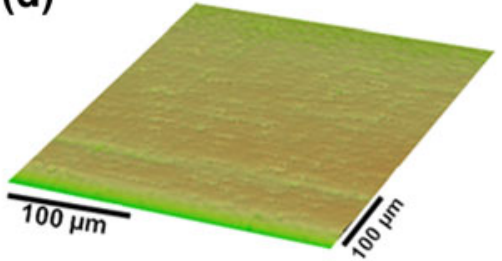

(f)

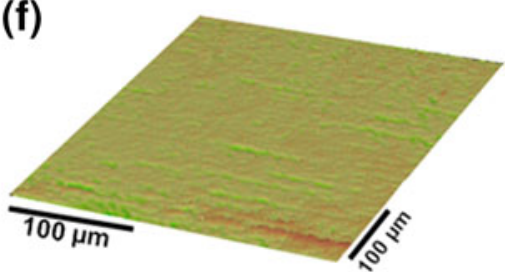

(h)

Fig. 3 Representative laser scanning confocal microscope system (LSCM) images of Ni-Ti wires. As-received: (a) smooth pattern, (c) dimple pattern, (e) crack pattern, and (g) scratch pattern. Soft drink-treated: (b) smooth pattern, (d) dimple pattern, (f) crack pattern, and (h) scratch pattern

Table 4 Mean values obtained from potentiostatic polarization plot of different $\mathrm{Ni}-\mathrm{Ti}$ archwires studied in artificial saliva solution

\begin{tabular}{|c|c|c|c|c|c|c|c|}
\hline \multirow[b]{2}{*}{$\mathrm{Ni}-\mathrm{Ti}$ archwires } & & \multicolumn{3}{|c|}{ Artificial saliva } & \multicolumn{3}{|c|}{ Artificial saliva + Soft drink } \\
\hline & & $i_{\text {corr }} \mu \mathrm{A} / \mathrm{cm}^{2}$ & $E_{\text {corr }}, \mathbf{m V}$ & $E_{\text {ocp }}, \mathrm{mV}$ & $i_{\text {corr }} \mu \mathrm{A} / \mathrm{cm}^{2}$ & $E_{\text {corr }}, \mathbf{m V}$ & $E_{\text {ocp }}, \mathbf{m V}$ \\
\hline Reflex SE & Smooth & -3.85 & -520 & +555 & -2.87 & -600 & +545 \\
\hline Nitinol Classic & Smooth & -3.00 & -515 & +568 & -2.84 & -601 & +524 \\
\hline Orthonol & Dimple & -1.67 & -565 & +450 & -1.38 & -691 & +479 \\
\hline Align XF & Dimple & -0.88 & -579 & +520 & -0.79 & -674 & +488 \\
\hline Memoria & Crack & -1.36 & -624 & +401 & -1.08 & -796 & +409 \\
\hline Titanol SE & Crack & -0.67 & -657 & +321 & -0.11 & -809 & +405 \\
\hline Tensic & Scratch & -0.22 & -708 & +320 & +0.03 & -894 & +307 \\
\hline Nitinol HA & Scratch & -0.59 & -606 & +290 & +0.24 & -887 & +301 \\
\hline
\end{tabular}

enamel, because the bracket-archwire set complicates the selfcleaning mechanisms and the saliva rinsing effect.

The results referred to the main objective of this study show soft drink at low $\mathrm{pH}$ to exert corrosive action on the surface of $\mathrm{Ni}-\mathrm{Ti}$ orthodontic archwires, although in different ways depending on the surface pattern. In previous research with other corrosive media (Ref 16, 19), it was shown that the manufacturer of $\mathrm{Ni}$-Ti wires exerts a statistically significant influence upon corrosion resistance, since the as-received commercial Ni-Ti archwires had different surface morphologies (Ref 6, 7, 16). The results obtained agree with this influence of the manufacturer upon corrosion resistance. Nevertheless, previous studies (Ref 5-7, 10, 12, 13, 16, 19) relate corrosion to the brands of archwires studied, using only one to four archwires from different manufacturers. This study may have some advantages, since a given pattern indicates a given surface finish, which allows us to group several brands or manufacturers within the same pattern. The surface finish is related to the manufacturing process which, in turn, is related to corrosion resistance (Ref 6, 22, 28). Therefore, the surface pattern should be taken into account both in present (Ref 29) and in future corrosion research. 
Rating of the surface patterns in terms of corrosion resistance from low to high is as follows: crack, scratch, dimple, and smooth. In the crack and scratch patterns, these defects are responsible for the increase in total surface defects, producing an increase in the discontinuities in the archwire surface (Fig. 1f-h). In the dimple pattern, there is an increase in the number of defects, producing a more irregular surface, but without increasing the surface discontinuities (Fig. 1d). The smooth pattern shows no signs of corrosion (Fig. 1b). There is some debate in the case of fluoride corrosion (the most widely studied type of corrosion) between those authors (Ref $3,16,18$ ) who consider surface defects produced during the manufacturing process to be the cause of corrosion and those who do not (Ref 7, 19). Upon reviewing the results, it is seen that surface defects can play an important role in archwires corrosion by carbonated drinks. Further studies are needed to confirm this hypothesis (involving ion leaching, polarization curves, etc.). During manufacture of the archwires, those processes that lead to the formation of surface defects, especially cracks, should be avoided.

Crack and scratch patterns presented greater corrosion behavior due to the high surface energy produced by plastic deformation, especially in the tip, resulting in high stress corrosion. Thermodynamically, the zones with more energy are more susceptible to electrochemical attack. Cracks also can lead to crevice corrosion. However, other surface patterns presented greater corrosion resistance, as is the case of smooth and dimple patterns. From these results it can be observed that the role of roughness in corrosion behavior is not significant in comparison with the defects.

In the fluoride corrosion mechanism, which has been extensively studied in the last decade, the fluoride ions can deteriorate the passive film of the titanium oxide surface $(\operatorname{Ref} 7$, $12,14,15)$ by hydrogen absorption (Ref 14), decreasing the corrosion resistance of the alloy and hence its biocompatibility (Ref 1-3). In this case, the carbonated drink has a low pH (2.5) and contains acids. The total acid level (known as titratable acid), rather than the $\mathrm{pH}$, can be an important factor in corrosion because it determines the actual hydrogen ion availability (Ref 30) for interaction with the passive film, in a way similar to fluoride corrosion (Ref 6, 10, 11, 13). Most soft drinks contain one or more food acidulants; phosphoric and citric acid are common but malic, tartaric, and other organic acids also may be present (Ref 31). These acids are responsible for the characteristics of Ni-Ti archwires corrosion produced by soft drinks.

The corrosive effects of soft drinks are mainly reflected by an increase in the pre-existing as-received surface defects (Table 2). The present study recorded the generalized formation of small cracks, similar to the pits produced during fluorine corrosion (Ref 5, 13,15), but only on the archwires with a scratch pattern (Fig. 1h). The crack pattern yielded greater increases in surface defect content from the pre-existing cracks (Fig. 1f). Cracks filled with impurities in the as-received archwires grow and become more pronounced. The as-received impurities have been previously described and related to archwire deterioration by other authors (Ref 32). In the absence of further studies, the most pronounced soft drink effect upon the Ni-Ti alloy is seen to be its ability to produce or enlarge cracks which generate surface discontinuities and have detrimental effects on the passive film (Ref 15). Cracks act as crevices that induce corrosion through the formation of a differential aeration cell. In the archwires with a dimple pattern (Fig. 1c, d), and although an increase in number is observed, there is no surface discontinuity (crevices) and, coupled with the smooth pattern, this is the most corrosion resistant pattern. In future research it would be interesting to measure the effect of ion leaching upon the average diameter and mass of the archwires in order to better understand the corrosiveness and effects of soft drink on the passive layer. On comparing these findings with those found during fluoride corrosion, several relevant differences are observed. The most frequent consequences of fluoride immersion are a general (Ref 5, 13-15) or localized attack (Ref 10,15) in the form of pits. Another characteristic effect is the change in color: dark stains (Ref 13), white spots (Ref 9, 13-15), or dark spots that disappear after the immersion tests in as-received archwires (Ref 12-14, 32, 33). Such changes in color described during corrosion in fluoride media were not found in the present study. A hypothesis to prove is that soft drinks, unlike fluoride, use pre-existing defects as nucleation sites for corrosion-cracks being the most important defects because of the existence of a crevice.

Regarding the increase in roughness after immersion in soft drink, correlations with the crack pattern were found (Table 3). The increase in roughness is related to corrosion ( $\operatorname{Ref} 3,6,7$ ), although not the initial roughness ( $\operatorname{Ref} 3,7,19)$. The results obtained are in agreement with the findings referred to the dimple pattern, with high initial roughness, which does not significantly affect post-immersion roughness. Nevertheless, this is in discrepancy with other investigators (Ref 20) who point to initial roughness as a factor related to corrosion. On the other hand, the increase in roughness is not only related to the increase in the number of defects. In the dimple and scratch patterns the number of defects increase but not so roughness. The explanation for this is that the surface occupied by the defects in some archwires represents about $10 \%$ of the total surface. Thus, roughness depends on the number of defects but also on the remaining surface. Taking into account that immersion in fluoride solution produces a generalized increase in roughness that is dependent upon concentration and $\mathrm{pH}$ (Ref 5,6), in the as-received archwires with few surface defects the increase in roughness essentially depends on the processes taking place on the surface free of defects. In exposure to soft drink, an increase in roughness in the crack pattern is observed where the number of pre-existing defects is significant. This increase can influence post-immersion roughness. It would be interesting to study the changes in roughness produced by fluorated solutions and to compare them with those produced by carbonated drinks, in the same way that the difference has been studied between the actions of chloride-containing solutions on $\mathrm{Ni}-\mathrm{Ti}$ archwires and those exposed to fluoride media (Ref 5). The rougher surface condition in fluoride can be ascribed to the general corrosion of $\mathrm{Ni}$-Ti alloy in fluoride solutions (Ref 5). As the acid media in soft drink and fluoride are different, there should be differences between them.

It may be noted that the potentials in an open circuit of the all archwires adopt positive values, and consequently the $\mathrm{Ni}-\mathrm{Ti}$ archwires studied remain in their immune range. The higher the current density at a given potential, the more prone the material is to corrosion. Smooth and dimple patterns had the most passive $\left(-2.87,-2.84,-1.38\right.$, and $\left.-0.79 \mu \mathrm{A} / \mathrm{cm}^{2}\right)$ and scratch the most active $\left(+0.03,+0.24 \mu \mathrm{A} / \mathrm{cm}^{2)}\right.$ critical current density values in artificial saliva with fluoride solution.

The differences in current density at a given potential between smooth and dimple patterns are due to the internal stresses produced in the surface of the Ni-Ti by the machining process, which favor the corrosion processes. 
Observed surface changes cannot be directly related to changes in the mechanical properties of Ni-Ti archwires (Ref 13). Neither surface defects nor roughness can be considered the only factors involved in corrosion; surface residual stress, the amount of residue and the degree of homogeneity of microstructures (Ref 5, 7, 19), among other factors, must also be taken into account. The orthodontist should instruct the patient on carbonated drink intake during treatment, suggesting the use of a straw to minimize the corrosive effect on $\mathrm{Ni}-\mathrm{Ti}$ archwires.

\section{Conclusions}

In conclusion, soft drinks with low $\mathrm{pH}$ values exert corrosive action on the surface of $\mathrm{Ni}$-Ti orthodontic archwires, although in different ways depending on the surface pattern. Archwires with cracked or scratched surface patterns are the least corrosion resistant. Cracks as pre-existing manufacturing defects show the greatest surface deterioration, due to the internal energy stored. However, the initial roughness of archwires is not related to the increase in roughness when they are exposed to soft drink. The cracked surface pattern moreover shows the greatest increase in roughness; therefore, cracks should be avoided in the archwire surface pattern. The absence of standard surface treatment protocols for $\mathrm{Ni}-\mathrm{Ti}$ results in variability in the surface finish, which in turn responds differently to corrosion. Such protocols should be helpful in securing better quality surfaces.

\section{Acknowledgments}

The authors thank Dr. Juan Luis Ribas (LSCM expert) and the Center for Technology and Innovation Research, University of Seville (CITIUS), for their collaboration in this study.

\section{References}

1. D.J. Wever, A.G. Veldhuizen, J. de Vries, H.J. Busscher, D.R. Uges, and J.R. van Horn, Electrochemical and Surface Characterization of a Nickel-Titanium Alloy, Biomaterials, 1998, 19(7-9), p 761-769

2. J. Wang, N. Li, G. Rao, E.H. Han, and W. Ke, Stress Corrosion Cracking of NiTi in Artificial Saliva, Dent. Mater, 2007, 23(2), p 133137

3. H.H. Huang, Y.H. Chiu, T.H. Lee, S.C. Wu, H.W. Yang, and K.H. Su, Ion Release from NiTi Orthodontic Wires in Artificial Saliva with Various Acidities, Biomaterials, 2003, 24(20), p 3585-3592

4. H.H. Huang, Surface Characterizations and Corrosion Resistance of Nickel-Titanium Orthodontic Archwires in Artificial Saliva of Various Degrees of Acidity, J. Biomed. Mater. Res. A, 2005, 74(4), p 629-639

5. X. Li, J. Wang, E.H. Han, and W. Ke, Influence of Fluoride and Chloride on Corrosion Behavior of NiTi Orthodontic Wires, Acta Biomater, 2007, 3(5), p 807-815

6. H.H. Huang, Variation in Surface Topography of Different NiTi Orthodontic Archwires in Various Commercial Fluoride-Containing Environments, Dent. Mater, 2007, 23(1), p 24-33

7. T.H. Lee, T.K. Huang, S.Y. Lin, L.K. Chen, M.Y. Chou, and H.H. Huang, Corrosion Resistance of Different Nickel-Titanium Archwires in Acidic Fluoride-Containing Artificial Saliva, Angle Orthod., 2010, 80(3), p 547-553

8. Y.H. Kwon, Y.D. Cheon, H.J. Seol, J.H. Lee, and H.I. Kim, Changes on NiTi Orthodontic Wired due to Acidic Fluoride Solution, Dent. Mater. J., 2004, 23(4), p 557-565

9. A. Ramalingam, V. Kailasam, S. Padmanabhan, and A. Chitharanjan, The Effect of Topical Fluoride Agents on the Physical and Mechanical Properties of NiTi and Copper NiTi Archwires. An In Vivo Study, Aust. Orthod. J., 2008, 24(1), p 26-31
10. N. Schiff, B. Grosgogeat, M. Lissac, and F. Dalard, Influence of Fluoridated Mouthwashes on Corrosion Resistance of Orthodontics Wires, Biomaterials, 2004, 25(19), p 4535-4542

11. N. Schiff, M. Boinet, L. Morgon, M. Lissac, F. Dalard, and B. Grosgogeat, Galvanic Corrosion Between Orthodontic Wires and Brackets in Fluoride Mouthwashes, Eur. J. Orthod., 2006, 28(3), p 298-304

12. I. Watanabe and E. Watanabe, Surface Changes Induced by Fluoride Prophylactic Agents on Titanium-Based Orthodontic Wires, Am. J. Orthod. Dentofacial Orthop., 2003, 123(6), p 653-656

13. M.P. Walker, R.J. White, and K.S. Kula, Effect of Fluoride Prophylactic Agents on the Mechanical Properties of Nickel-Titanium-Based Orthodontic Wires, Am. J. Orthod. Dentofacial Orthop., 2005, 127(6), p 662-669

14. K. Yokoyama, K. Kaneko, K. Moriyama, K. Asaoka, J. Sakai, and M. Nagumo, Hydrogen Embrittlement of Ni-Ti Superelastic Alloy in Fluoride Solution, J. Biomed. Mater. Res. A, 2003, 65(2), p 182-187

15. N. Schiff, B. Grosgogeat, M. Lissac, and F. Dalard, Influence of Fluoride Content and $\mathrm{pH}$ on the Corrosion Resistance of Titanium and Its Alloys, Biomaterials, 2002, 23(9), p 1995-2002

16. M. Es-Souni, T. Es-Souni, and H. Fischer-Brandies, On the Properties of Two Binary NiTi Shape Memory Alloys. Effects of Surface Finish on the Corrosion Behaviour and In Vitro Biocompatibility, Biomaterials, 2002, 23(14), p 2887-2894

17. A. Wichelhaus, M. Geserick, R. Hibst, and F.G. Sander, The Effect of Surface Treatment and Clinical Use on Friction in NiTi Orthodontic Wires, Dent. Mater, 2005, 21(10), p 938-945

18. Y. Oshida, R.C. Sachdeva, and S. Miyazaki, Microanalytical Characterization and Surface Modification of TiNi Orthodontic Archwires, Biomed. Mater. Eng., 1992, 2(2), p 51-69

19. H.H. Huang, Variation in Corrosion Resistance of Nickel-Titanium Wires from Different Manufacturers, Angle Orthod., 2005, 75(4), p 661-665

20. F. Widu, D. Drescher, R. Junker, and C. Bourauel, Corrosion and Biocompatibility of Orthodontic Wires, J. Mater. Sci. Mater. Med., 1999, 10(5), p 275-281

21. M. Es-Souni, H. Fischer-Brandies, N. Koc, O. Bo, K. Rätzke. Chemische Zusammensetzung, Umwandlungsverhalten und mechanische Biegeeigenschaften ausgewählter kieferorthopädischer NiTi-Drahtbögen. IOK 2001, 33, p 87-106

22. A. Paúl, C. Abalos, A. Mendoza, E. Solano, and F.J. Gil, Relationship Between the Surface Defects and the Manufacturing Process of Orthodontic Ni-Ti Archwires, Mater. Lett., 2011, 65(23-24), p 3358-3361

23. I. Van Eygen, B.V. Vannet, and H. Wehrbein, Influence of a Soft Drink with Low pH on Enamel Surfaces: An In Vitro Study, Am. J. Orthod. Dentofacial Orthop., 2005, 128(3), p 372-377

24. J.A. von Fraunhofer and M.M. Rogers, Dissolution of Dental Enamel in Soft Drinks, Gen. Dent., 2004, 52(4), p 308-312

25. ISO-standard 10993-15:2000 "Biological evaluation of medical devices. Part 15: Identification and quantification of degradation products from metals and alloys"

26. J.D. Shenkin, K.E. Heller, J.J. Warren, and T.A. Marshall, Soft Drink Consumption and Caries Risk in Children and Adolescents, Gen. Dent., 2003, 51(1), p 30-36

27. L. Harnack, J. Stang, and M. Story, Soft Drink Consumption Among US Children and Adolescents: Nutritional Consequences, J. Am. Diet. Assoc., 1999, 99(4), p 436-441

28. C. Bourauel, T. Fries, D. Drescher, and R. Plietsch, Surface Roughness of Orthodontic Wires Via Atomic Force Microscopy, Laser Specular Reflectance, and Profilometry, Eur. J. Orthod., 1998, 20(1), p 79-92

29. C. Abalos, A. Paúl, A. Mendoza, E. Solano, and F.J. Gil, Influence of Topographical Features on the Fluoride Corrosion of Ni-Ti Orthodontic Archwires, J. Mater. Sci.: Mater. Med., 2011, 22(12), p 2813-2821

30. N.X. West, J.A. Hughes, and M. Addy, Erosion of Dentine and Enamel In Vitro by Dietary Acids: The Effect of Temperature, Acid Character, Concentration and Exposure Time, J. Oral Rehabil., 2000, 27(10), p 875-880

31. A.J. Rugg-Gunn and J.H. Nunn, Diet and Dental Erosion. Nutrition, Diet and Oral Health, Oxford University Press, Hong Kong, 1999, p 32

32. M.R. Grimsdottir and A. Hensten-Pettersen, Surface Analysis of Nickel-Titanium Archwire Used In Vivo, Dent. Mater., 1997, 13(3), p 163-167

33. T. Eliades, G. Eliades, A.E. Athanasiou, and T.G. Bradley, Surface Characterization of Retrieved NiTi Orthodontic Archwires, Eur. J. Orthod., 2000, 22(3), p 317-326 